\title{
COVID-19, food insecurity, and diet-related diseases: Can syndemic theory inform effective responses? A case study
}

Special issue:

Food as a Tool for Social Change

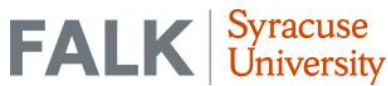

\author{
J. Robin Moon, ${ }^{a}$ Craig Willingham ${ }^{b}$ \\ City University of New York
}

Shqipe Gjevukaj c

Bronx Partners for Healthy Communities

\author{
Nicholas Freudenberg $\mathrm{d} *$ \\ City University of New York
}

Submitted January 3, 2021 / Revised February 18 and March 19, 2021 / Accepted March 22, 2021 /

Published online September 16, 2021

Citation: Moon, J. R., Willingham, C., Gjevukaj, S., \& Freudenberg, N. (2021). COVID-19, food

insecurity, and diet-related diseases: Can syndemic theory inform effective responses? A case study.

Journal of Agriculture, Food Systems, and Community Development, 10(4), 55-71.

https://doi.org/10.5304/jafscd.2021.104.028

Copyright (C) 2021 by the Authors. Published by the Lyson Center for Civic Agriculture and Food Systems. Open access under CC-BY license.

\begin{abstract}
New York City was hit hard by the COVID-19 pandemic. Although the immediate health burden was devastating, we posit that its long-term impact will be even greater, because the rapid spread of COVID-19 both depended on and exacerbated other deep-seated inequities related to food and broader living conditions. Using the Bronx as a

\footnotetext{
a J. Robin Moon, Adjunct Associate Professor, CUNY Graduate School of Public Health and Health Policy; robin.moon@sph.cuny.edu

b Craig Willingham, Deputy Director, CUNY Urban Food Health Policy; craig.willingham@sph.cuny.edu

c Shqipe Gjevukaj, Project Manager, Bronx Partners for Healthy Communities, Bronx, NY; sgjevukaj@sbhny.org

$\mathrm{d} *$ Corresponding author: Nicholas Freudenberg, Distinguished Professor and Director, CUNY Urban Food Policy Institute; CUNY Graduate School of Public Health and Health Policy;

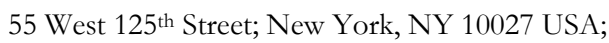
nick.freudenberg@sph.cuny.edu
} Policy Institute; CUNY Graduate School of Public Health and
\end{abstract}

case study, we explore the intersection of the pandemic with two other persistent problems: food insecurity and diet-related diseases, a constellation we label the COVID-Food Syndemic. Syndemic theory focuses on the common causes and biological and social interactions between two or more health problems. We hypothesize that with its focus on the common social causes of ill health, this approach can inform and strengthen the synergies between community-based, activistdriven solutions and municipal government responses, thus reducing the burden of ill health in the Bronx. We suggest that combining these two approaches can more fully mobilize the social changes that are needed in the food system and beyond to interrupt the fundamental drivers of this syndemic and capitalize on the respective strengths of government, civil society, and activists.

\section{Keywords}

Syndemic, Food Insecurity, Diet-related Diseases, COVID-19, Pandemic, Community Mobilization, Municipal Government, Food System Change 


\section{Introduction}

In March 2020, the novel coronavirus SARS-CoV2 began its devastating spread in New York City. Over the following few weeks, rates of infection, illness, hospitalizations, and deaths from COVID19 increased exponentially. By the end of 2020, COVID-19 had infected 436,692 New York City residents, hospitalized $8.29 \%$ of the city's population, and killed 25,186 New York City residents (New York Times, 2021), making New York City one of the hardest-hit areas of the 2020 waves of the pandemic (Solis et al., 2020).

As devastating as the immediate health burden imposed by the pandemic was (Bailey \& Moon, 2020), its long-term impact will be even greater, in part because the rapid spread of COVID-19 both depended on and exacerbated other deep-seated inequities in New York City. In this report, we explore the intersection of the COVID-19 pandemic with two other persistent problems: high rates of food insecurity and diet-related diseases (DRD). For more than 60 years, food insecurity, hunger, and the disproportionate impact of chronic diseases have been visible consequences - and causes - of urban poverty in the United States (Baumgartner, 1969; Harrington, 1962). Our investigation is centered in the Bronx, the poorest of New York City's five boroughs, with the highest burden of each of the three problems.

Centering our inquiry in the Bronx, we examine in what ways the concept of syndemic, defined as "two or more epidemics ... interacting synergistically and contributing, as a result of their interaction, to excess burden of diseases in a population" (Singer \& Clair, 2003), can lead to more effective public health programs and public policies to reduce the burden of disease that this syndemic we call the COVID-Food Syndemic - food insecurity, DRD, and COVID-19-imposes on the people of the Bronx. More broadly, we examine how the concept of syndemics can strengthen actions by municipal government and civil society to address the drivers of persistent racial and ethnic inequities in health in urban America. Such cross-cutting actions can also help frame and develop a new urban food agenda that promotes intersectoral, multilevel, and democratic responses to food crises (Sonnino \& Coulson, 2020).
We make the case for two basic premises. First, we argue that a coordinated response to the common drivers of these three related epidemics that constitute the COVID-Food Syndemic will be more effective than addressing each epidemic separately. Second, we argue that strengthening and aligning the many community-based responses that residents and activists in the Bronx have already launched in response to these three epidemics as well as their underlying causes, with government responses to the syndemic, will in the long run be more effective than either strategy alone. By examining how community activists in the Bronx use food justice, anti-racism, and equity as frameworks in responding to the intersecting problems that make the Bronx the poorest and least healthy of New York State's 62 counties, we aim to show that aligning community-driven efforts at social change with municipal policy initiatives can contribute to more transformative changes in food and other social policies.

\section{Profile of the Bronx}

A brief description of the Bronx provides the background for this investigation. In 2019, 1.4 million people lived in the Bronx, about $17 \%$ of New York City's population. The average life expectancy in the Bronx for the period 2010-2015 was 78.3 years, the shortest of the city's five boroughs and the second shortest of all New York State counties. In the Bronx, neighborhoods with the shortest life expectancy averaged 69.4 years, while the areas with the longest averaged 86.1 years, a gap of 16.7 years. Compared to New York City as a whole (Table 1), the Bronx included higher concentrations of people at risk for one or more of the three health problems under consideration in this study.

This concentration of populations at risk is, in turn, the consequence of several social and economic trends in New York City and the nation, including growing income inequality; increasing poverty; persistent segregation; wide inequities in access to and quality of housing, education, and healthcare; the rise in low-wage labor; and social policies such as tax cuts for the wealthy and cuts in safety-net programs (Bailey \& Moon, 2020). Over the past several decades, these trends have created social and economic conditions that have facili 
Table 1. Comparison of the Bronx and New York City on Selected Demographic Indicators

\begin{tabular}{lcc}
\hline Indicator (Year) & Bronx (\%) & New York City (\%) \\
\hline Race/Ethnicity (2019) & 55.9 & 29.1 \\
\hline Latino/Hispanic & 29.3 & 21.7 \\
\hline Black & 9.3 & 31.9 \\
\hline White & 3.5 & 14.3 \\
\hline Asian & 2 & 3 \\
\hline Other & 19.6 & 32.7 \\
\hline Live in owner-occupied housing unit (2014-2018) & 32,203 & 27,012 \\
\hline Population density, in persons per sq. mile (2010) & 72 & 81.6 \\
\hline Graduate of high school or higher (2014-2018) & 11.1 & 6.8 \\
\hline Disability for those under 65 (2014-2018) & US\$38,085 & US\$60,762 \\
\hline Household mean income (2014-2018) & 27.3 & 18.9 \\
\hline Persons in poverty (2018) & & \\
\hline
\end{tabular}

Source: U.S. Census Bureau, Quick Facts;

www.census.gov/quickfacts/fact/table/newyorkcitynewyork,bronxcountybronxboroughnewyork,kingscountybrooklynboroughnewyork,newy orkcountymanhattanboroughnewyork, queenscountyqueensboroughnewyork,richmondcountystatenislandboroughnewyork/PST045219

tated higher rates of ill health in the Bronx compared to New York City as a whole, and stark racial and ethnic inequities within the Bronx. For the past decade, the Bronx has been ranked consistently as the least healthy of New York State's counties according to the U.S. County Health Rankings

Table 2. COVID-19 Case Rates and Fatality Rates by Race in the Bronx Compared to New York City (per 100,000) between March 1, 2020, and October 21, 2020

\begin{tabular}{lcccc}
\hline & \multicolumn{5}{c}{ Case Rates } \\
\cline { 2 - 5 } & Bronx Rate & \% of Bronx Cases & Citywide Rate & \% of Citywide Cases \\
\hline Asian & $1,666.9$ & 2.7 & 854.3 & 9.7 \\
\hline White & $2,245.0$ & 9.8 & $1,323.5$ & 34.3 \\
\hline Black & $2,584.3$ & 32.7 & $1,877.2$ & 13.2 \\
\hline Latinx & $2,607.2$ & 54.8 & $2,076.9$ & 42.7 \\
\hline
\end{tabular}

Fatality Rates

\begin{tabular}{lcccc}
\hline & Bronx Rate & \% of Bronx Deaths & Citywide Rate & $\begin{array}{c}\text { \% of Citywide } \\
\text { Deaths }\end{array}$ \\
\hline Asian & 169.0 & 2.6 & 112.5 & 3.1 \\
\hline White & 169.0 & 12.3 & 125.1 & 26.2 \\
\hline Black & 305.8 & 35.4 & 249.9 & 33.7 \\
\hline Latinx & 268.9 & 49.8 & 267.2 & 37.0 \\
\hline
\end{tabular}

Source: New York City Department of Health and Mental Hygiene (DOHMH). (2020, November 6). COVID-19 data: Fatalities by county. Retrieved November 7, 2020, from https://covid19tracker.health.ny.gov
(University of Wisconsin Population Health Institute, 2020a).

COVID-19 in the Bronx: Infections, Hospitalizations, and Deaths

By the end of October 2020, COVID-19 case and fatality rates per capita in the Bronx were $31.4 \%$ and $22 \%$, respectively, higher than the citywide rates New York City Department of Health and Mental Hygiene, 2020). By the end of April (the peak of the outbreak in New York), Bronx residents were twice as likely to be hospitalized or die of COVID-19 than residents of neighboring Manhattan (Wadhera et al., 2020). By October 2020, more than 5,000 Bronx residents had died from COVID-19. Table 2 demonstrates the uneven distribution of the case 
and fatality rates by race compared to the citywide rates, showing that case rates among Black and Latinx residents in the Bronx were 13\% higher and fatality rates were $16 \%$ higher than citywide rates.

\section{Food Insecurity in the Bronx}

For at least the last 70 years, the Bronx has grappled with high rates of food insecurity, unemployment, housing instability, and inadequate social welfare benefits (Wallace \& Wallace, 2000). Food insecurity is a symptom of limited access to healthy food, a problem with multiple causes, including lack of both income and culturally appropriate and appealing options for healthy nutrition. The conditions that triggered multiple health crises include discriminatory housing red-lining and the planned shrinkage of city services; the city's 1970s fiscal crisis and resulting austerity measures that included cuts in public services in poor neighborhoods; and the withdrawal of the federal government from public housing support in the 1980s (Bailey \& Moon, 2020; Freudenberg et al., 2006; Wallace, 1988).

Over the years, these conditions allowed arson, HIV, crack and heroin addiction, and homicide and injuries to emerge and flourish in the Bronx. Like COVID-19 infection today, these health and social problems were both the cause and consequence of high rates of housing instability and homelessness, unemployment, financial insecurity, and food insecurity (Wallace \& Wallace, 2000). Moreover, the pandemic has reinforced this negative cycle; the economic shutdown caused massive unemployment with resulting financial insecurity. New safety-net programs were often inadequate to meet the needs of the most vulnerable populations, contributing to more food insecurity, ill health, and COVID-19 morbidity and mortality (Parrott, 2021).

Prior to the COVID-19 pandemic, the rate of people living in poverty was $47 \%$ higher in the Bronx than citywide (27\% vs. $18.9 \%$ ) (U.S. Census Bureau, 2019), and the proportion of people who spent more than $50 \%$ of their income on housing was $24 \%$ higher in the Bronx than citywide $33 \%$ vs. 27.6\%) (Citizens' Committee for Children of New York, 2018). In 2018, the Bronx was considered the least food-secure borough, with $26 \%$ of residents and $38 \%$ of children living in foodinsecure homes, compared to $13 \%$ and $18 \%$ citywide, respectively (Hunger Free America, 2018). In the United States, poverty is a consistent predictor of higher rates of hunger and food insecurity (Gundersen \& Ziliak, 2018).

In the Bronx, rates of food hardship, defined as "sometimes or often running out of food, or worrying about running out of food without having enough money to buy more," varied from 35\% to $70 \%$ of the sample of households recruited from the 12 community districts in the Bronx. (Gordis et al, 2019). On May 13, 2020, New York City estimated that the number of hungry New Yorkers had doubled in the previous 10 weeks to more than 2 million (Mann, 2020). While county-specific food insecurity data by race are not available, in New York State, between April 23 and July 21, 2020, up to $25 \%$ of Latinx and up to $22 \%$ of Black residents experienced household food scarcity, almost four times higher than rates for their white counterparts (U.S. Census Bureau, 2020).

In continuing efforts to slow the spread of the virus, all New York's non-essential businesses were closed on March 22, leading to a significant increase in unemployment. By the end of June 2020, the Bronx experienced the highest unemployment rate in New York City, at 24.7\% (New York State Department of Labor, 2020b), up from $5 \%$ in 2019. This is also the highest unemployment rate across all 62 counties (New York State Department of Labor, 2020a). Some projections show that the economic fallout of the crisis will force nearly $40 \%$ more New York City residents and nearly $50 \%$ more New York City children to face food insecurity in 2021 (Lehrer, 2020) although the size, scale and efficacy of pandemic relief programs will influence the actual rates.

With the continued decrease in available household income, in a population with limited to no financial reserves, the need for food assistance was on the rise. By the end of April 2020, emergency food providers (EFPs) such as food pantries and soup kitchens experienced nearly double the demand pre-COVID-19, and a 90\% increase in first-time visitors (Feeding America, 2020). However, with $50 \%$ of Bronx-based EFPs closing due to shortage of volunteers or closed facilities - the 
highest proportion in the city-and $90 \%$ of which were in high-needs communities, the Bronx continued to grapple with food access.

At the end of 2019, the federal Supplemental Nutrition Assistance Program (SNAP) covered on average approximately 1.5 million recipients in New York City (New York City Open Data, 2019). Although monthly participation in New York City started to decline in 2019, the pandemic drastically altered this trend. By April 2020, more than 68,000 New York City residents enrolled in SNAP, a 4.6\% increase from March, making it the largest onemonth increase in SNAP participation that New York City has experienced since 2008 (Hunger Free America, 2020). The increase in the Bronx is even more pronounced: by June 2020, $28.3 \%$ of Bronx residents were active SNAP recipients compared to $20 \%$ citywide, accounting for one-third of the city's SNAP recipients (Hunger Free America, 2020). Between June 2019 and June 2020, the number of Bronx individuals enrolled in SNAP increased by 8\% (New York City Open Data, 2018). However, since data are not available on the proportion of either food-insecure or food-secure Bronx residents now enrolled in SNAP, it is not possible to ascertain the extent to which the SNAP program in the Bronx is meeting the needs of food-insecure individuals or households.

In sum, already-high rates of food insecurity in the Bronx were further elevated by steep increases in pandemic-triggered unemployment, school closures, shortages of emergency food distribution channels, and inadequate supplemental welfare programs. While the federal government renewed some safety-net programs in early 2021, the persistence of the underlying weaknesses of the city's economy, especially in the Bronx (Parrott, 2021), makes it likely that absent intervention, high levels of food insecurity will continue in this borough.

\section{Diet-Related Diseases in the Bronx}

While COVID-19 widened inequities in premature death and preventable illness concentrated in the Bronx, the pandemic itself did not cause this disproportionate burden. Prior to the pandemic, compared to the citywide population, the people of the Bronx experienced higher rates of a variety of illnesses, including conditions associated with diet and nutrition (Table 3).

Bronx residents experienced rates of adult obesity, adult diabetes prevalence, adult hypertension prevalence, and diabetes mortality at more than 1.2 to 1.45 times the rate of all city residents. Bronx residents were also more likely to consume $\geq 1$ daily portion of sugary beverages than were all New York City residents, consumption patterns associated with higher rates of diet-related diseases (DRD) (New York City Department of Health and

Table 3. Rates of Selected Health Conditions, The Bronx, and New York City, 2018

\begin{tabular}{lccc}
\hline Health and Behavioral Indicators & Bronx rate (\%) & $\begin{array}{c}\text { New York City rate } \\
(\%)\end{array}$ & Ratio of Bronx to NYC \\
\hline Child Obesity & 24 & 20 & 1.34 \\
\hline Adult Obesity & 32 & 24 & 1.33 \\
\hline Type 2 Diabetes Prevalence & 16 & 11 & 1.45 \\
\hline Type 2 Diabetes Mortality, age-adjusted & 22.0 & 18.3 & 1.2 \\
\hline Hypertension Prevalence & 36 & 28 & 1.29 \\
\hline Premature Deaths $<75$ & 52.1 & 44.3 & 1.18 \\
\hline Avoidable Hospitalizations & 20.9 & 10.3 & 2.02 \\
\hline Adults without Health Insurance & 12 & 12 & 1.0 \\
\hline Adults without Needed Medical care & 12 & 10 & 1.2 \\
\hline Adults Consuming $\geq 1$ daily Sugary Beverages & 32 & 23 & 1.39 \\
\hline
\end{tabular}

Sources: NYC DOHMH, Community Health Survey; New York City Department of Health and Mental Hygiene. Community Health Profiles by Borough, 2018, https://www1.nyc.gov/site/doh/data/data-publications/profiles.page 
Mental Hygiene, 2018).

Healthcare indicators add to the story. Although Bronx residents had equivalent rates of health insurance coverage as all New Yorkers, they were twice as likely to experience avoidable hospitalizations (see Table 3), suggesting that actual access to care (e.g., available transportation, childcare, paid sick time), timely access to care, and quality of care contributed to poorer outcomes, including premature death.

The higher prevalence of DRD in the Bronx prior to the pandemic contributed to the higher burdens of COVID-19 on the residents. Bronx residents were more likely to report obesity, hypertension, diabetes, hyperlipidemia, and heart disease than all city residents, all of which have been identified as risk factors for COVID-19 mortality (New York State Department of Health and Mental Hygiene, 2020). For each of these co-morbidities, diet is a critical contributing factor. Moreover, for some low-income households, a recent national study showed, the pandemic exacerbated diets associated with obesity and DRD, a reciprocal relationship between the pandemic and DRD (Flanagan et al., 2021).

Other evidence suggests that residents of the Bronx have less access to affordable healthy food than other New Yorkers. Based on the 2020 food environment index score (University of Wisconsin Population Health Institute, 2020b), a component of the County Health Rankings which examines access to healthy foods and levels of food insecurity prior to the pandemic, the Bronx was rated as having one of the least healthy food environments in New York City. The ratio of bodegas (corner grocers) to supermarkets is higher in the Bronx than elsewhere in the city. Since bodegas generally stock more inexpensive, unhealthy food and charge higher prices for healthy food than supermarkets, this higher ratio may contribute to the reduced availability of affordable healthy food (Morland \& Filomena, 2007). A recent study found that bodegas and dollar stores clustered in low-income areas of the Bronx with high rates of DRD (Cohen et al., 2020). Between 2011 and 2016, the number of fast food restaurants in the Bronx increased by $11 \%$ (U.S. Department of Agriculture [USDA]

Economic Research Service, 2020).
At first glance, high rates of DRD in the Bronx, usually associated with overnutrition, and high rates of food insecurity, usually associated with undernutrition, may seem contradictory. But a growing body of evidence suggests that DRD and food insecurity have common causes and often coexist in the same families and populations (Weaver \& Fasel, 2018). Moreover, DRD is associated with micronutrient deficiencies as well as too many calories, leaving those with constrained food budgets at risk of both.

The COVID-19 pandemic elevated the already high risk of morbidity and mortality from DRD in the Bronx via three pathways. First, by increasing unemployment, the pandemic reduced household income for food. Since healthy food is often more expensive than less healthy food (Drewnowski \& Barratt-Fornell, 2004), this made it harder for lowincome households - those with the highest risk for and burdens of DRD—-to afford healthier food; not surprisingly, they substitute less expensive, less healthy food. Pandemic-related increases in food prices further reduced household food budgets (Asymkos, 2021). Second, the pandemic led institutional food programs and EFPs to substitute shelf-stable and easily transported processed products for fresh produce (Hunter College New York City Food Policy Center et al., 2020), increasing the portion of calories from calorie-dense foods high in fat, sugar, and salt, ingredients associated with an elevated risk of DRD. Finally, the pandemic reduced access to routine primary care (e.g., diabetes management and support, obesity and nutrition counseling, blood pressure monitoring, medication refills) that controls DRD, diminishing opportunities for primary and secondary prevention of these conditions (Wright et al., 2020).

\section{The COVID-Food Syndemic}

Three essential characteristics of syndemics are shared population risk predicated by persistent structural inequity, common social drivers for multiple conditions, and synergistic interactions among disease processes (Singer \& Clair, 2003). In this section, we describe three ways that the COVIDFood Syndemic in the Bronx illustrates these defining features. 
First, historical and persistent structural racism and economic inequities (Bailey \& Moon, 2020) in the Bronx have created segregated housing and prolonged disinvestment in the community. This has concentrated populations of color in the Bronx, who are further marginalized by employment, wages, tax and credits, and other social policies and structures that widen economic inequalities. They are affected by multiple existing and emerging social drivers of poor health (Figure 1), creating characteristics that amplify risk for the three health outcomes that constitute this syndemic: food insecurity, DRD, and COVID-19 (Hill et al., 2021).

Second, syndemics are characterized by biological interactions between disease states and interactions between those biological processes and the social, economic, and power inequities that shape the distribution of diseases (Gravlee, 2020). Biosocial interactions within syndemics move in both directions: social inequities shape the risk of COVID-19 infection, illness, and death, and the pandemic also led to devastating job losses that have disproportionately affected Black and Latinx Americans, further increasing their risk for housing instability, food insecurity, and widening educational inequities (Gravlee, 2020).

Third, COVID-19 exacerbates racially inequitable access to healthcare and disrupts prevention and management of DRD, conditions more common in Black and Latinx populations. As a result, racial and economic inequities in health widen. Food insecurity increases the consumption of less expensive, less healthy food, increasing the risk for DRD, and in turn, DRDs put individuals with COVID-19 infection at increased likelihood of serious illness or death. Income inequality and precarious work (Hawkley, 2018) exacerbate food insecurity, but also force workers to accept working conditions that increase the risk of COVID-19 infection. By using syndemic theory to identify and tackle the common social drivers, this analysis provides a rationale and roadmap for a coordinated and unified response to these three threats to health (Singer et al., 2020).

\section{Limits of Siloed Municipal Responses in Reducing Syndemic}

Municipal governments have long been characterized by and criticized for a siloed approach to gov-

\section{Figure 1. Common Social Drivers of Food Insecurity, DRD, and COVID-19}

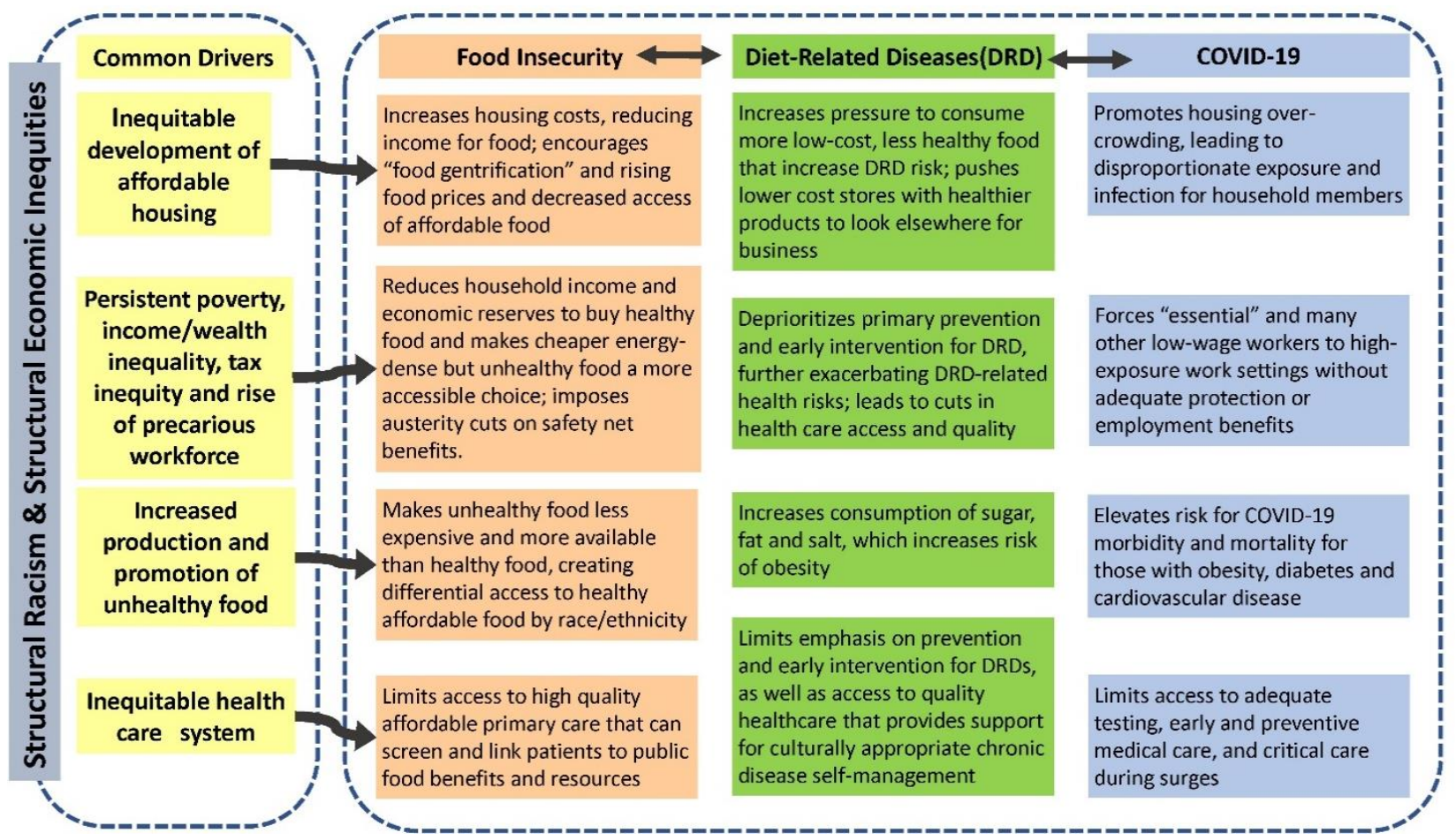


ernance and service delivery. Siloization persists in part because it can have advantages in specific cases: it enables the application of specialized knowledge to technical problems, facilitates political control over bureaucracies, and can contribute to more rapid decision-making and implementation (Scott, 2020). However, siloed approaches often miss opportunities for more synergistic and effective responses to common drivers. They limit the potential for mobilizing key community assets such as neighborhood organizations, social justice advocates, and grassroots community leaders. They deter building support for scaling up effective programs and policies, making them sustainable, and linking them to other sectors, tasks that require the all-of-government approaches that challenge siloed bureaucracies (Wolf-Fordham, 2020). In recent years, global and national health organizations have urged a "health in all policies" approach to ensure more effective implementation of intersectoral, multilevel interventions (Gase et al., 2013), Finally, siloed programs and policies are also vulnerable to budget cuts, especially during economic crises when elites insist that austerity in public spending is required (Korfmacher, 2019).

These limitations include programs and policies that:

- Depend on emergency and charitable programs that are reactive and not designed to be sustainable. The prepandemic food pantries and soup kitchens in low-income communities are unable to end food insecurity nor are they designed for long-term health (Poppendieck, 1999). The Bronx has had the highest number of EFPs as a Band-Aid solution for its long-standing food insecurity issues, while having some of the worst DRD outcomes.

- Often focus on remediating immediate consequences rather than addressing the more fundamental common social drivers that perpetuate vicious cycles of worsening health and health disparities. For example, despite the clear evidence that the fundamental causes of diabetes and diabetes disparities are the social determinants of health (Haire-Joshu \& Hill-Briggs, 2019), New
York Medicaid dollars cannot be spent on true barriers to healthcare access such as transportation, childcare, or paid sick leave.

- Use siloed approaches, missing opportunities for integration, efficiency, and synergistic impact and greater efficiency. Although Medicaid has created new programs to address social determinants, these approaches have been modestly funded and poorly coordinated (Bachrach et al., 2016), illustrating the challenges of using Medicaid to improve population health (Kartika \& Rosenthal, 2017). New York State Medicaid funding, for example, fails to support community-based food organizations; until the pandemic school lunch programs have not worked with community-based food vendors; and emergency housing does not accommodate basic public health practices such as bathing, privacy, and safety. In the Bronx and around the nation, this lack of community-level intersectoral collaboration compromises the efficacy of social interventions (Minkler, 2018).

- Rely on top-down or bottom-up strategies rather than a combination of the two, missing both the power of whole-government approaches and the political impact of community-driven mobilizations. Thus, New York state and city governments work separately on COVID-19 testing, PPE distribution, and vaccination. Essential workers in food, education, and healthcare are not systematically protected, and uncoordinated and episodic philanthropic handouts often fail to consult community residents and leaders about their needs (North Bronx Mutual Aid, 2020).

- Fail to recognize and mobilize the substantial knowledge and assets of communities and their leaders to combat threats to their residents' health. For example, government agencies often rely on one-way communication with communities and do not engage residents in designing emergency responses. When more equitable partnerships are created, they may achieve positive results, as demonstrated by the Claremont Healthy 
Village Initiative, a multisectoral partnership based in the Bronx (Realmuto et al., 2020).

\section{Role of Community Activism in Reversing the Syndemic}

Unlike governments' tendency of working in silos, we argue that community activism tends to approach issues from a more holistic, communitydriven lens, and thus embrace comprehensive solutions to reverse the syndemic. For the last 50 years, the Bronx has been an incubator of food and social justice activism. In the 1970s and 1980s, United Bronx Parents fought to expand and improve school food programs (Povitz, 2019). In the late 1990s, La Familia Verde, a coalition of community gardens in the Bronx, started to grow food and then expanded to take on other tasks including community development and voter registration ( $\mathrm{La}$ Familia Verde, n.d.). After the U.S. County Health Ranking Report reported in 2009 that the Bronx had the lowest health ranking of all of New York State counties, a coalition of health, communitybased, and faith-based organizations, as well as elected officials, created Not62: The Campaign for a Healthy Bronx, a communitywide mobilization designed to lift the Bronx from its low ranking (Olumhense \& Choi, 2020). Improving food environments was a key part of its platform.

Today, thousands of Bronx individuals and organizations already work to improve their standard of living and take on the drivers of the COVIDFood Syndemic. Table 4 lists a few examples of Bronx organizations that are already embracing a syndemic perspective by taking on common drivers (e.g., structural racism, economic inequity, affordable housing, precarious work, food system, healthcare system) that shape the COVID-Food Syndemic. They offer programs and services related to all three outcomes of the syndemic (food insecurity, DRD, and COVID-19) and assist their constituencies in addressing the intersecting impact of the three conditions, for example by preventing evictions, finding healthy affordable food, and enrolling in comprehensive primary care. These civil society activist approaches help community residents to utilize the categorical public programs to make more integrated and meaningful improvements in their living conditions. Many are led by
Black and Latina women, constituencies with long track records of improving living conditions in the Bronx and throughout urban America (Povitz, 2019).

Most importantly, by mobilizing community residents and relying on their experience in addressing deep-seated community problems, these organizations tap into the human capital that is the most valuable resource of low-income urban communities. While these groups have not explicitly articulated a syndemic perspective, their actions demonstrate an understanding of shared fundamental causes, the reality of the intersecting manifestation of food insecurity, DRD, and COVID-19 in the lived experience of many Bronx residents, and the power of a comprehensive and collective social justice approach to improving health. In the future, health activists may find that using a syndemic framework might help them to enlist public officials and policymakers in generating more systemic responses to the health challenges that the Bronx and other low-income urban communities face.

By supporting, nurturing, and leveraging this energy and passion, and by finding ways to align its power with the capacity of public officials, public agencies, and local businesses willing to work for a healthier and more equitable Bronx, New York City, and nation, health professionals and community advocates can contribute to reversing the multifaceted syndemic that threatens the future of the Bronx and urban America.

\section{A New Syndemic-Informed Approach: Recommendations}

In the short run, Bronx residents, community organizations, and national, state, and local governments will continue to launch categorical, often siloed responses to reduce the problems posed by food insecurity, DRD, and the COVID-19 out of necessity. But the limits of these responses, illustrated by temporary expansions of emergency food programs and repeated extensions of eviction moratoria, and the profound challenge the COVIDFood Syndemic poses to the well-being of the Bronx, require public health and healthcare practitioners, researchers, and advocates to consider other approaches. By using the glaring spotlight of 
Table 4. Selected Current Bronx Community Initiatives to Address COVID-Food Syndemic

\begin{tabular}{|c|c|c|c|c|c|}
\hline \multirow[b]{2}{*}{ Name of Initiative } & \multirow[b]{2}{*}{ Description and Web Link } & \multicolumn{4}{|c|}{ Addresses } \\
\hline & & COVID-19 & $\begin{array}{c}\text { Food } \\
\text { Insecurity }\end{array}$ & DRD & Other \\
\hline $\begin{array}{l}\text { Bronx Health } \\
\text { Reach }\end{array}$ & $\begin{array}{l}\text { This coalition of more than } 70 \text { community-based } \\
\text { organizations, health care providers, faith-based } \\
\text { institutions, housing, and social service agencies } \\
\text { works with community members, coalition members, } \\
\text { partners, and funders to eliminate racial and ethnic } \\
\text { disparities in health outcomes in the Bronx; key } \\
\text { founder of Not62: The Campaign for a Healthy Bronx } \\
\text { (see below). } \\
\text { https://institute.org/bronx-health-reach/about/ }\end{array}$ & $x$ & $x$ & $x$ & $\begin{array}{l}\text { Access to quality } \\
\text { primary care }\end{array}$ \\
\hline $\begin{array}{l}\text { Bronx Rising } \\
\text { Initiative }\end{array}$ & $\begin{array}{l}\text { This effort distributes critical resources across the } \\
\text { Bronx in response to the COVID-19 pandemic's } \\
\text { disproportionate impact on the borough. It blends } \\
\text { mutual aid, vaccine campaigns, volunteerism, } \\
\text { philanthropy, and small business development. } \\
\text { https://www.bronxrisinginitiative.com/ }\end{array}$ & $x$ & $\mathrm{x}$ & & $\begin{array}{l}\text { Economic } \\
\text { development }\end{array}$ \\
\hline Bronx Works & $\begin{array}{l}\text { A human service organization and settlement house } \\
\text { that helps individuals and families improve their } \\
\text { economic and social well-being by feeding, sheltering, } \\
\text { teaching, preparing for workforce, and supporting } \\
\text { residents to build a stronger community. } \\
\text { http://www.bronxworks.org/ }\end{array}$ & $x$ & $x$ & $x$ & $\begin{array}{l}\text { Employment } \\
\text { Housing }\end{array}$ \\
\hline $\begin{array}{l}\text { Mott Haven } \\
\text { Community } \\
\text { Fridge }\end{array}$ & $\begin{array}{l}\text { An outdoor refrigerator that provides all community } \\
\text { members with 24-hour, no-questions-asked access to } \\
\text { fresh food. } \\
\text { https://www.facebook.com/motthavencommunityfrid } \\
\text { ge/ }\end{array}$ & $x$ & $x$ & $x$ & \\
\hline $\begin{array}{l}\text { New Settlement } \\
\text { Apartments }\end{array}$ & $\begin{array}{l}\text { This settlement house provides housing to more than } \\
1,000 \text { families and offers services in education, } \\
\text { college access, youth development, arts, workforce } \\
\text { development, community organizing, wellness, and } \\
\text { food. Its recent neighborhood health plana called for } \\
\text { an expansion of local farmers markets, improvements } \\
\text { in food retail outlets, and creation of a local food } \\
\text { policy council. https://newsettlement.org/ }\end{array}$ & $x$ & $\mathrm{X}$ & $x$ & $\begin{array}{l}\text { Housing, } \\
\text { employment, } \\
\text { family support }\end{array}$ \\
\hline $\begin{array}{l}\text { Not62: The } \\
\text { Campaign for a } \\
\text { Healthy Bronx }\end{array}$ & $\begin{array}{l}\text { Through collaboration and partnership across multiple } \\
\text { sectors, Not62: The Campaign For a Healthy Bronx } \\
\text { seeks to address the social and economic conditions } \\
\text { that affect the overall quality of life, and help create } \\
\text { an environment where Bronx residents can attain their } \\
\text { highest level of health. } \\
\text { https://www.facebook.com/not62BX/ }\end{array}$ & $x$ & $x$ & $x$ & $\begin{array}{l}\text { Community } \\
\text { organizing and } \\
\text { political advocacy }\end{array}$ \\
\hline $\begin{array}{l}\text { Rivers Run } \\
\text { Community } \\
\text { Garden }\end{array}$ & $\begin{array}{l}\text { Grows food adjacent to Coop City, the largest coop- } \\
\text { erative housing development in the world. During the } \\
\text { pandemic, it distributed Milk Crate Gardens to seniors } \\
\text { living in the area so they could grow a small amount of } \\
\text { fresh food. } \\
\text { https://www.facebook.com/RiversRun }\end{array}$ & $x$ & $x$ & $x$ & $\begin{array}{l}\text { Health needs of } \\
\text { older people }\end{array}$ \\
\hline
\end{tabular}

a https://newsettlement.org/food/wp-content/uploads/sites/5/2020/12/Jerome-Neighborhood-Health-PlanRecommendations_20201016_Signed.pdf 
the pandemic to illuminate different responses to business-as-usual approaches to restoring the health and economy of the Bronx and reducing its persistent social and economic inequities, a syndemic-informed strategy may provide lessons that could benefit all urban America.

In doing so, the people of the Bronx and other low-income communities can begin to overcome some of the limitations of current responses to the health threats that constitute the COVID-Food Syndemic.

Our analysis of the cumulative impact of food insecurity, DRD, and COVID-19 on the Bronx suggests several components for more holistic, comprehensive, and effective responses. Rather than posing incremental or transformative approaches as a binary choice, a more comprehensive strategy would help health professionals, researchers, and advocates to align and coordinate interventions that can ameliorate the downstream consequences of the syndemic while also opening paths to more transformative upstream changes (Freudenberg et al., 2015). In responding to COVID-19 and previous health crises, community residents, sometimes with the support of academics, have used community-based participatory research and community organizing to contribute evidence and mobilization that has led to meaningful changes (Michener et al., 2020; Minkler, 2018; Wallerstein et al., 2017). In addition, rather than seeing municipal government and communitybased civil society and activist groups only as contestants battling to shape more effective policy responses, these actors can align their efforts to create synergies that rely on the differing strengths of each approach. For example, the Pandemic EBT (P-EBT) program (USDA Food and Nutrition Service, 2020) uses federal funding to enable families of schoolchildren-regardless of their income or documentation status-to use a voucher to replace school food missed because of closed schools, which opens a path for ending the exclusion of many immigrants from public food assistance.

What might such a municipal governmentcommunity-aligned approach include? First, it should make increasing access to healthy affordable food a priority by expanding and improving distri- bution channels for vulnerable populations to ensure that they do not experience hunger or food insecurity. As long as unhealthy products are cheaper and more available than healthy food, it will be difficult to reduce the influence of poor diets on the health of residents of low-income areas in the Bronx and elsewhere. Key strategies for making healthy food more available include improving institutional food in schools, senior centers, jails, and hospitals; subsidizing healthy food through public farmers markets, community supported agriculture, and other fresh healthy food suppliers; and expanding, streamlining, and sustaining existing municipal food programs that promote food equity. For example, P-EBT vouchers could be used to create incentives for purchasing more fruits and vegetables, an innovation that could sustain local farmers markets and greengrocers, thus supporting local businesses that make healthy food more available (Fraser et al., 2021).

Prior to the pandemic, the New York City Mayor's Office of Food Policy coordinated several programs designed to improve access, purchasing power, and nutrition education (City of New York, 2019). In addition to federal resources, in FY 2020 the city set aside US $\$ 976$ million—about $1 \%$ of the city's budget-to deploy an array of programs to bring healthier food options to low-income neighborhoods, incentivize healthier food choices by increasing purchasing power at farmers markets, and increase nutrition and cooking education (CUNY Graduate School of Public Health \& Health Policy, \& CUNY Urban Food Policy Institute, 2019). These programs have been implemented through various interagency efforts led by the New York City Department of Health and Mental Hygiene through its Neighborhood Health Action Centers.

To date, however, these programs, which illustrate the potential for community-municipal government partnerships, have not been brought to scale, even in low-income neighborhoods, thus missing the opportunity for a synergistic impact on health and local economic development. Even though these programs are motivated to drive collective impact and create comprehensive solutions, they have not had the resources for meaningful evaluation nor equitable expansion. By encouraging 
the city government to expand and scale these programs, community activists could support a costeffective public investment in improving access to healthy food in neighborhoods hardest hit by the syndemic. Since these programs already engage neighborhood organizations to extend their reach, investing in both food programs and infrastructure development for these groups could contribute to stronger local economies, improved food access, and greater community capacity for problemsolving.

In the long run, shrinking the inequities generated by the syndemic will save taxpayers money. During the current economic crisis, large food companies, many of which have gotten taxpayer relief during the pandemic, avoided taxes through tax breaks, paid their workers such low wages that they had to rely on SNAP and Medicaid to survive, and aggressively promoted unhealthy products to populations at the highest risk of COVID-19 and DRD (Global Health Advocacy Incubator, 2020). Making corporate tax policies more equitable and reforming a tax code that enables food companies to deduct the expenses of marketing unhealthy food to vulnerable populations (Sonneville et al., 2015) could reduce incentives for practices that exacerbate the syndemic.

Second, a comprehensive approach should increase affordability, quality, and access to comprehensive primary care. Primary care should be the first place people go to seek healthcare, whether to treat symptoms of illness or prevent illness. Effective primary care can identify food insecurity through screening, provide early intervention services for DRD, and link individuals to food distribution programs, nutrition and obesity prevention counseling and education, and SNAP or WIC enrollment. By intervening before health problems become substantive threats to well-being, selfsufficiency, and productivity, integrated primary care support can be most effective for at-risk patients. Healthcare payers (Medicaid being the largest) can play a significant role in supporting the integration of these services. Managed-care plans have access to the populations who are most affected by this syndemic and can identify increasing demand for healthcare in order to advocate for an increased supply and the resources to support it.
In the Bronx, community organizations already work with health plans to reduce asthma and diabetes hospitalizations and engage patients with DRD in hospitals' fitness and nutritional cooking programs (Mitchell, 2020; SBH Health \& Wellness Center, n.d.). These programs should be scaled up to further reduce preventable hospitalization and healthcare costs. To date, state initiatives to expand access to primary care have operated mostly through academic medical centers, organizations that often put their institutional needs ahead of the needs of the community. By assisting communitybased organizations to claim a larger voice in redesigning primary care to meet their needs (Myers et al., 2019), health professionals and activists can modify these currently asymmetrical power relationships.

Third, a comprehensive strategy should improve pay, benefits, living conditions, and safety for workers who live or work in the Bronx. This approach would increase pay and require minimum wages; enforce occupational safety and health policies; increase the supply and affordability of safe, quality housing; increase subsidies for child care; and offer subsidies for public employment. Leaving essential workers with subminimum wages, limited or no employment benefits, and dangerous working conditions elevates the risk for food insecurity, DRD, and COVID-19 for a substantial portion of the Bronx's workforce. Substandard housing heightens the infection risk of these workers' families, and such housing is still severely unaffordable, reducing the disposable income that could otherwise go toward feeding their families. Another way of increasing income is to expand and sustain economic stimulus support and public benefits to increase the affordability of healthy food. By aligning Bronx food justice activism with New York's rich history of labor activism, these forces could work with city and state governments to strengthen recent gains in living-wages laws, paid sick leave, and workers protection (Greenhouse, 2018) that have especially benefited low-wage food workers in the Bronx.

Finally, a comprehensive plan created collaboratively by the government and civil society must make dismantling systemic racism a priority. In the Bronx, the apartheid organization of food, health- 
care, housing, and employment creates a cascade of risks and adverse consequences. This constellation helps ensure the Bronx remains the least healthy county in New York State. Beginning to dismantle the myriad public policies, norms, and institutional practices that maintain health inequities is an essential step toward ending the COVID-Food Syndemic in the Bronx. To break the vicious, synergistic cycle of the COVID-Food Syndemic, a new approach must tackle the historic, fundamental drivers of the syndemic, racism and economic inequality, as well as the emerging social determinants of health equity - what social epidemiologists call the causes of the causes (Braveman \& Gottlieb, 2014). By moving beyond only symptomatic, proximal manifestations of the problem, this approach promises meaningful improvements in health and health equity over the long run.

Taking on the most fundamental drivers of the COVID-Food Syndemic will also require changes in formal and informal governance. City officials and community leaders will need to create new spaces in which they can forge common agendas. During the first months of the pandemic, some city agencies did use new technologies to engage more fully with leaders and frontline workers, but these discussions reverted to the more one-way, business-as-usual format as the response was routinized. On the civil society side, new alliances also emerged. The New York COVID-19 Food Coalition brought together dozens of food justice and food security organizations, many in the Bronx, to identify common problems, share best practices, and advocate for more forceful responses to the inequitable impact of the pandemic. The group also cosponsored a forum on food policy for candidates for the city's 2021 mayoral election, an event that forced the candidates to become familiar with key food policy issues (Geringer-Sameth, 2021). These new collaborative efforts could serve as leverage points for sustainable transformation (Abson et al., 2017). By continuing to develop intersectoral, cross-cutting processes for debating and defining pandemic responses, these groups can nurture the ongoing interactions needed to build a sustainable process for addressing upstream determinants of the COVID-Food Syndemic.

In sum, for the past several decades, the Bronx has tried mostly uncoordinated, mostly downstream, mostly top-down approaches to reducing its most serious threats to well-being. To date, these approaches have not ameliorated the health ranking of the Bronx, nor mobilized sufficient political will and power to reverse the trends that put residents of the Bronx at egregious risk. Our analysis of the COVID-Food Syndemic suggests that a more effective approach would integrate topdown with bottom-up strategies, engage residents and community organizations already working for social change more fully, take on the common social drivers of the area's most serious health and social problems, and make dismantling racism a top priority. The organizational and political obstacles to such a strategy are formidable. But the evidence to date suggests that the business-as-usual approach will doom the Bronx to continuing generations of poverty, inequities, and poor health. COVID-Food Syndemic not only illuminates the limits of the current approach, but also creates opportunities and momentum for more transformative changes. In the Bronx, the building blocks for such an approach are in place. By leveraging these assets now, civil society, municipal government, and the flourishing social movements that are tackling inequity can lay the foundation for healthier, more equitable communities.

\section{Acknowledgments}

We gratefully acknowledge the many helpful suggestions from participants in the webinar on food justice in the Bronx organized by Not62: The Campaign for a Healthy Bronx, ${ }^{a}$ the Bronx advocacy organization where an earlier version of this paper was presented. We especially thank Charmaine Ruddock, Tanya Fields, and Karen Washington, three leaders of the fight for food and health justice in the Bronx, for their insights at that webinar. The ideas we present are our own and we take responsibility for any omissions or errors. No funding was provided for this report.

a https://www.facebook.com/not62BX/ 


\section{References}

Abson, D. J., Fischer, J., Leventon, J., Newig, J., Schomerus, T., Vilsmaier, U., Wehrdenn, H. V., Abernethy, P., Ives, C. D., Jager, N. W., \& Lang, D. J. (2017). Leverage points for sustainability transformation. Ambio, 46(1), 30-39. https://doi.org/10.1007/s13280-016-0800-y

Asymkos, S. (2021, February 16). High food prices are part of a 'one-two punch' for struggling Americans. Yahoo Finance, https://finance.yahoo.com/news/high-food-prices-struggling-americans-211552448.html

Bachrach, D., Guyer, J., \& Levin A. (2016). Medicaid coverage of social interventions: A road map for states [Issue brief]. Manatt Health. https://nyshealthfoundation.org/wp-content/uploads/2017/12/medicaid-coverage-ofsocial-interventions-issue-brief-july-2016.pdf

Bailey, Z. D., \& Moon, J. R. (2020). Racism and the political economy of COVID-19: Will we continue to resurrect the past? Journal of Health Politics, Policy and Law, 45(6), 937-950. https://doi.org/10.1215/03616878-8641481

Baumgartner, L. (1969). One hundred years of health: New York City, 1866-1966. Bulletin of the New York Academy of Medicine, 45(6), 555-586. https://www.ncbi.nlm.nih.gov/pmc/articles/PMC1750450/

Braveman, P., \& Gottlieb, L. (2014). The social determinants of health: It's time to consider the causes of the causes. Public Health Reports, 129(Suppl 2), 19-31. https://doi.org/10.1177/00333549141291S206

Citizens' Committee for Children of New York. (2018). Keeping track online: The status of New York City children: Severe rent burden. https://data.cccnewyork.org/data/map/74/severe-rent-burden\#74/a/2/116/40/a/a

City of New York. (2019). Food Metrics Report 2019. https://www1.nyc.gov/assets/foodpolicy/downloads/pdf/Food-Policy-Report-2019.pdf

Cohen, N., Chrobok, M., \& Caruso, O. (2020). Google-truthing to assess hot spots of food retail change: A repeat crosssectional street view of food environments in the Bronx, New York. Health Place, 62, Article 102291. https://doi.org/10.1016/i.healthplace.2020.102291

CUNY Graduate School of Public Health \& Health Policy, \& CUNY Urban Food Policy Institute. (2019). Food and the New York. City budget: A review and analysis of municipal budget allocations in fiscal years $2019 \& 2020$. https://static1.squarespace.com/static/572d0fcc2b8dde9e10ab59d4/t/5db8f8495e89a65debae77da/157240327468 4/CUFPI FBNYC Report Full 10-29-2019.pdf

Drewnowski, A., \& Barratt-Fornell, A. (2004). Do healthier diets cost more? Nutrition Today, 39(4), 161-168. https://doi.org/10.1097/00017285-200407000-00006

Feeding America. (2020). State-by-state resource: The impact of coronavirus on food insecurity. https://feedingamericaaction.org/resources/state-by-state-resource-the-impact-of-coronavirus-on-food-insecurity/

Flanagan, E. W., Beyl, R. A., Fearnbach, S. N., Altazan, A. D., Martin, C. K., \& Redman, L. M. (2021). The impact of COVID-19 stay-at-home orders on health behaviors in adults. Obesity, 29(2), 438-445. https://doi.org/10.1002/oby.23066

Fraser, K. T., Pereira, J., Poppendieck, J., Tavarez, E., Berg, J., \& Freudenberg, N. (2021). Pandemic EBT in New York State: Lessons from the 2019-2020 academic year and recommendations for 2020-2021 and beyond. CUNY Urban Food Policy Institute \& Hunger Free America. https://www.cunyurbanfoodpolicy.org/news/2021/1/19/p-ebt-policy-brief

Freudenberg, N., Fahs, M., Galea, S., \& Greenberg, A. (2006). The impact of New York City's 1975 fiscal crisis on the tuberculosis, HIV, and homicide syndemic. American Journal of Public Health, 96(3), 424-434. https://doi.org/10.2105/AJPH.2005.063511

Freudenberg, N., Franzosa, E., Chisholm, J., \& Libman, K. (2015). New approaches for moving upstream: How state and local health departments can transform practice to reduce health inequalities. Health Education \& Behavior, 42(Suppl. 1), 46S-56S. https://doi.org/10.1177/1090198114568304

Gase, L. N., Pennotti, R., \& Smith, K. D. (2013). "Health in All Policies": Taking stock of emerging practices to incorporate health in decision making in the United States. Journal of Public Health Management and Practice, 19(6), 529 540. https://doi.org/10.1097/PHH.0b013e3182980c6e

Geringer-Sameth, E. (2021, February 10). Democratic mayoral candidates offer ideas for addressing food insecurity. Gotham Gazette. https://www.gothamgazette.com/city/10154-democratic-mayoral-candidates-ideas-hunger-unhealthy-food 
Global Health Advocacy Incubator. (2020). Facing two pandemics: How big food undermined public health in the era of COVID-19. https://advocacyincubator.org/two-pandemics/

Gordis, S., Collyer, S., \& Wimer, C. (2019). Mapping hunger in New York City: A look at the rate of food hardship in New York City Neighborhoods. Poverty Tracker, Columbia Population Researh Center, \& Robin Hood. https://robinhoodorg-production.s3.amazonaws.com/uploads/2019/11/PovertyTracker Mapping-Hunger-1.pdf

Gravlee, C. C. (2020). Systemic racism, chronic health inequities, and COVID-19: A syndemic in the making? American Journal of Human Biology, 32(5), Article e23482. https://doi.org/10.1002/ajhb.23482

Greenhouse S. (2018, January 9). Fast-food workers claim victory in a New York labor effort. New York Times, p. B2. https://www.nytimes.com/2018/01/09/business/economy/fast-food-labor.html

Gundersen, C., \& Ziliak, J. P. (2018). Food insecurity research in the United States: Where we have been and where we need to go. Applied Economic Perspectives and Policy, 40(1), 119-135. https://doi.org/10.1093/aepp/ppx058

Haire-Joshu, D., \& Hill-Briggs, F. (2019). The next generation of diabetes translation: A path to health equity. Annual Review of Public Health, 40, 391-410. https://doi.org/10.1146/annurev-publhealth-040218-044158

Harrington, M. (1962). The other America: Poverty in the United States. Simon and Schuster.

Hawkley, D. (2018). The detrimental health and well-being consequences of employment precariousness: The role of working conditions in amplifying health disparities. American Journal of Medical Research, 5(2), 70-75. https://doi.org/10.22381/AJMR52201810

Hill, M. A., Sowers, J. R., \& Mantzoros, C. S. (2021). Commentary: COVID-19 and obesity pandemics converge into a syndemic requiring urgent and multidisciplinary action. Metabolism, 114, Article 154408. https://doi.org/10.1016/j.metabol.2020.154408

Himmelgreen, D., Romero-Daza, N., Heuer, J., Lucas, W., Salinas-Miranda, A. A., \& Stoddard, T. (2021). Using syndemic theory to understand food insecurity and diet-related chronic diseases. Social Science \& Medicine. Advance online publication. https://doi.org/10.1016/j.socscimed.2020.113124

Hunger Free America. (2018). The uneaten Big Apple: Hunger's high cost in NYC: New York City bunger report, 2018.

Hunger Free America. (2020, June 10). In April, NYC had largest one-month actual increase in SNAP food aid participation in modern history [Blog post].

Hunter College New York City Food Policy Center, Laurie M. Tisch Center for Food, E., \& Policy., \& CUNY Urban Food Policy Institute. (2020). New York food 20/20: Vision, research, and recommendations during COVID-19 and beyond. https://static1.squarespace.com/static/572d0fcc2b8dde9e10ab59d4/t/5f7b27b9e0c3e05f19c5442f/160190662446 4/ny2020-finalv2.pdf

Kartika, T., \& Rosenthal, J. (2017). Using DSRIP to improve population health. National Academy for State Health Policy. https://www.nashp.org/using-dsrip-to-improve-population-health/

Korfmacher, K. S. (2019). Bridging silos: Collaborating for environmental bealth and justice in urban communities. MIT Press.

La Familia Verde. (n.d.). Mission and History. Retrieved November 2020 by http://www.lafamiliaverde.org/about-us.html

Lehrer, B. (2020, August 11). New York's hunger problem [Radio episode]. New York Public Radio. https://www.wnyc.org/story/new-yorks-hunger-problem/

Mann, B. (2020, May 21). In New York City, 2 million residents face food insecurity, officials say. NPR. https://www.npr.org/sections/coronavirus-live-updates/2020/05/21/860312565/in-new-york-city-2-millionresidents-face-food-insecurity-officials-say

Michener, L., Aguilar-Gaxiola, S., Alberti, P. M., Castaneda, M. J., Castrucci, B. C., Harrison, L. M., Hughes, L. S., Richmond, A., \& Wallerstein, N. (2020). Engaging with communities-Lessons (re) learned from COVID-19. Preventing Chronic Disease, 17, Article E65. https://doi.org/10.5888/pcd17.200250

Minkler, M. (Ed.). (2018). Community organizing and community building for health and welfare (3rd Ed.). Rutgers University Press.

Mitchell, A. (2020, September 17) Saint Barnabas Health \& Wellness Center to open this October. Bronx Times. https://www.bxtimes.com/saint-barnabas-health-and-wellness-center-to-open-this-october/ 
Morland, K., \& Filomena, S. (2007). Disparities in the availability of fruits and vegetables between racially segregated urban neighbourhoods. Public Health Nutrition, 10(12), 1481-1489. https://doi.org/10.1017/S1368980007000079

Myers, N., Burke, G. C., Sharp, M., Gilman, M., \& Shearer, C. (2019). DSRIP promising practices: Strategies for meaningful change for New York Medicaid. United Hospital Fund. https://uhfnyc.org/publications/publication/dsrip-promising-practices/

New York City Department of Health and Mental Hygiene. (2018). Community health profiles by borough. Retrieved November 7, 2020, from https://www1.nyc.gov/site/doh/data/data-publications/profiles.page

New York City Department of Health and Mental Hygiene. (2020). COVID-19: Data main - NYC bealth. https://www1.nyc.gov/site/doh/covid/covid-19-data.page

New York City Open Data. (2018). Borough/community district report_SNAP population. https://data.cityofnewyork.us/Social-Services/Borough-Community-District-Report-SNAP-Population/jye8$\underline{\mathrm{w}} 4 \mathrm{~d} 7 /$ data

New York City Open Data. (2019). Borough/Community District Report - SNAP Population. https://data.cityofnewyork.us/Social-Services/Borough-Community-District-Report-SNAP-Population/jye8$\underline{\mathrm{w} 4 \mathrm{~d} 7 / \mathrm{data}}$

New York State Department of Health. (2020, November 6). [COVID-19] Fatalities by county. https://covid19tracker.health.ny.gov/views/NYS-COVID19-Tracker/NYSDOHCOVID-19TrackerFatalities? $\% 3$ Aembed $=$ yes $\& \% 3$ Atoolbar $=$ no $\& \% 3$ Atabs $=$ n

New York State Department of Labor. (2020a, October 15). NYS economy added 75,300 private sector jobs in September 2020 [Press release]. https://dol.ny.gov/news/nys-economy-added-75300-private-sector-jobs-september-2020

New York State Department of Labor. (2020b, July 21). State Labor Department Releases Preliminary June 2020 Area Unemployment Rates [Press release]. https://dol.ny.gov/system/files/documents/2021/03/press-release-2-june-2020-final.pdf

New York Times. (2021, January 2). New York City coronavirus map and case count. https://www.nytimes.com/interactive/2020/nyregion/new-york-city-coronavirus-cases.html

North Bronx Mutual Aid. (2020, June 18). Why NYC mutual aid workers are cutting ties with World Central Kitchen. Medium. https:/ /www.medium.com/@,northbronxmutualaid/why-nyc-mutual-aid-workers-are-cutting-ties-withworld-central-kitchen-335cfec40189

Olumhense E., \& Choi, A. (2020, April 3). Bronx residents twice as likely to die from COVID-19 in NYC. The City. https://www.thecity.nyc/health/2020/4/3/21210372/bronx-residents-twice-as-likely-to-die-from-covid-19-in-nyc

Parrott, J. A. (2021). New York City's Covid-19 economy will not snap back. Center for New York City Affairs. http://www.centernyc.org/reports-briefs/new-york-citys-covid-19-economy-will-not-snap-back

Poppendieck, J. (1999). Sweet charity? Emergency food and the end of entitlement. Penguin.

Povitz, L. D. (2019). Stirrings: How activist New Yorkers ignited a movement for food justice. University of North Carolina Press.

Realmuto, L., Weiss, L., Masseo, P., Madondo, K., Kumar, R., Beane, S., \& Pagán, J. A. (2020). "Hey, we can do this together": Findings from an evaluation of a multi-sectoral community coalition. Journal of Urban Health, 1-8. https://doi.org/10.1007/s11524-020-00473-3

SBH Health \& Wellness Center. (n.d). About the center. https://www.sbhwellnesscenter.org/about

Scott, I. (2020). Governing by silos. In Oxford Research Encyclopedia of Politics. https://doi.org/10.1093/acrefore/9780190228637.013.1414

Singer, M., Bulled, N., \& Ostrach, B. (2020). Whither syndemics? Trends in syndemics research, a review $2015-2019$. Global Public Health, 15(7), 943-955. https://doi.org/10.1080/17441692.2020.1724317

Singer, M., \& Clair, S. (2003). Syndemics and public health: Reconceptualizing disease in bio-social context. Medical Anthropology Quarterly, 17(4), 423-441. https://doi.org/10.1525/maq.2003.17.4.423

Solis, J., Franco-Paredes, C., Henao-Martínez, A. F., Krsak, M., \& Zimmer, S. M. (2020). Structural vulnerability in the U.S. revealed in three waves of COVID-19. The American Journal of Tropical Medicine and Hygiene, 103(1), 25-27. https://www.ajtmh.org/view/journals/tpmd/103/1/article-p25.xml 
Sonneville, K. R., Long, M. W., Ward, Z. J., Resch, S. C., Wang, Y. C., Pomeranz, J. L., Moodie, M. L., Carter, R., Stacks, G., Swinburn, B. A., \& Gortmaker, S. L. (2015). BMI and healthcare cost impact of eliminating tax subsidy for advertising unhealthy food to youth. American Journal of Preventive Medicine, 49(1), 124-134. https://doi.org/10.1016/i.amepre.2015.02.026

Sonnino, R., \& Coulson, H. (2020). Unpacking the new urban food agenda: The changing dynamics of global governance in the urban age. Urban Studies, 58(5), 1032-1049. https://doi.org/10.1177/0042098020942036

Strong, A. (2020). How New York City is feeding children on the front lines of a pandemic. https://www.foodandwine.com/news/new-york-city-school-children-free-food-coronavirus

U.S. Census Bureau. (2019). Quick facts: United States https://www.census.gov/quickfacts/fact/table/US/PST045219

U.S. Census Bureau. (2020). Household pulse survey interactive tool, food scarcity. https://www.census.gov/data-tools/demo/hhp/\#/?measures=FIR

U.S. Department of Agriculture Economic Research Service. (2020). Food Environment Atlas Fast-food Restaurants (\% change), 2011-2016. https://www.ers.usda.gov/data-products/food-environment-atlas/go-to-the-atlas/

University of Wisconsin Population Health Institute. (2020a). Bronx County, New York. Robert Wood Johnson Foundation. https://www.countyhealthrankings.org/app/new-york/2020/rankings/bronx/county/outcomes/overall/snapshot

University of Wisconsin Population Health Institute. (2020b). County Health Rankings and Roadmaps. Robert Wood Johnson Foundation. https://www.countyhealthrankings.org/app/newyork $/ 2020 /$ compare $/$ snapshot?counties=36 005\%2036 047\%2036 081\%2036 085\%2036 061

Wadhera, R. K., Wadhera, P., Gaba, P., Figueroa, J. F., Joynt Maddox, K. E., Yeh, R. W., \& Changyu, S. (2020). Variation in COVID-19 hospitalizations and deaths across New York City boroughs. JAMA Network, 323(21), 2192-2195. https://doi.org/10.1001/jama.2020.7197

Wallace, D., \& Wallace, R. (2000). Life and death in Upper Manhattan and the Bronx: Toward an evolutionary perspective on catastrophic social change. Environment and Planning A: Economy and Space, 32(7), 1245-1266. https://doi.org/10.1068/a32208

Wallace, R. (1988). A synergism of plagues: "Planned shrinkage," contagious housing destruction, and AIDS in the Bronx. Environmental Research, 47(1), 1-33. https://doi.org/10.1016/s0013-9351(88)80018-5

Wallerstein, N., Duran, B., Oetzel, J. G., \& Minkler, M. (Eds.). (2017). Community-based participatory research for health: Advancing social and health equity (3rd Ed.). Wiley.

Weaver, L. J., \& Fasel, C. B. (2018). A systematic review of the literature on the relationships between chronic diseases and food insecurity. Food and Nutrition Sciences, 9(5), 519-541. https://doi.org/10.4236/fns.2018.95040

Wolf-Fordham, S. (2020). Integrating government silos: Local emergency management and public health department collaboration for emergency planning and response. The American Review of Public Administration, 50(6-7), $560-567$. https://doi.org/10.1177/0275074020943706

Wright, A., Salazar, A., Mirica, M., Volk, L. A., \& Schiff, G. D. (2020). The invisible epidemic: Neglected chronic disease management during COVID-19. Journal of General Internal Medicine, 35, 2816-2817.

https://doi.org/10.1007/s11606-020-06025-4 